Cad.Est.Ling., Campinas, (44):223-238, Jan./Jun. 2003

\title{
O MONITORAMENTO DE PROBLEMAS DE COMPREENSÃO NA CONSTRUÇÃO DO TEXTO FALADO
}

\author{
JOSÉ GASTON HILGERT \\ (Universidade de Passo Fundo) ${ }^{1}$
}

Inge (uma biografia): a exuberância do saber emoldurada pela simplicidade do ser.

\begin{abstract}
RÉSUMÉ Cet article a pour objet l'analyse et la description de la manière dont est construit le texte parlé, dans des situations d'échange verbal au cours desquelles les interlocuteurs doivent gérer des problèmes de compréhension. Dans un premier temps, nous examinons la notion de compréhension, en partant du principe que, dans le texte parlé, la production des significations est déterminée par les contingences mêmes du déroulement de l'interaction. Afin de souligner le caractère progressif de la compréhension, nous présentons en premier lieu quelques situations paradigmatiques du fait que la compréhension est contrôlée par les interlocuteurs, au moyen d'une confirmation préventive. Ensuite, toujours en ce qui concerne le status nascendi du texte parlé, nous envisageons la notion de problème de compréhension. Finalement, nous abordons le thème central de cet article: nous analysons comment se déroule la vérification des problèmes de compréhension et présentons un modèle explicatif ainsi que des catégories de vérification.
\end{abstract}

\section{INTRODUÇÃO}

Este trabalho está em sintonia com inúmeros outros que, em vários projetos de pesquisa individuais ou coletivos ${ }^{2}$, investigam as estratégias de construção de textos falados. Tem ele o objetivo de descrever como os interlocutores, em sua ação interativa, monitoram as seqüências conversacionais em que resolvem problemas de compreensão.

Numa relação comunicativa, os falantes, para buscarem os objetivos ilocucionais que os põem em interação, têm, cada um, plena consciência de que seus enunciados, antes de levarem o interlocutor a crer, a responder, a agir e, antes de exercerem força argumentativa, explicativa, justificadora, precisam ser compreendidos pelo interlocutor $^{3}$. Por isso, em função de seus propósitos de comunicação, os falantes

${ }^{1}$ Agradeço ao DAAD e à FAPERGS pelo apoio que me deram para fazer um estágio, de janeiro a março de 2002, na Universidade de Freiburg, Alemanha. Este artigo é um dos resultados desse período de estudos. Falado.

${ }^{2}$ Entre os projetos coletivos destaquem-se o Projeto NURC/BR e o Projeto da Gramática do Português

${ }^{3}$ Cf. Motsch e Pasch 1987, p. 11-79. 
mantêm a compreensão sob constante controle no trabalho de formulação do texto. Seja individualmente, enquanto detentores do turno, seja em ações colaborativas, em momentos de negociação formulativa, eles monitoram, por meio de diferentes atividades, as escolhas discursivas, mormente as de natureza linguiística - é a estas que aqui se restringe o enfoque - para que elas sejam compreendidas no sentido com que foram inseridas em determinado ponto do processamento textual, dentro do contexto em que este se realiza. ${ }^{4}$

Com o objetivo mencionado serão analisadas as seqüências conversacionais ${ }^{5}$, em que se monitoram problemas de compreensão, de três inquéritos do Projeto NURC-RS, transcritos em Hilgert $1997^{6}$, os quais somam um total de 130 minutos de fala.

Do ponto de vista de sua estrutura, este trabalho discute, inicialmente, a noção de compreensão, com base no princípio de que a geração dos sentidos no texto falado é determinada pelas contingências do desdobramento da interação. Buscando evidenciar esse caráter processual da compreensão, analisam-se, inicialmente, alguns exemplos, para mostrar como ela é controlada, na evolução do texto, por meio de um monitoramento profilático. A seguir, sempre dentro da perspectiva de status nascendi do texto falado, discute-se a noção de problema de compreensão. À luz dessa fundamentação passa-se, depois de precisar o sentido de alguns termos, ao tema central deste artigo: a análise do monitoramento dos problemas de compreensão, com a definição de padrões e conseqüentes categorias de monitoramento. Nas considerações finais, além de se retomarem aspectos gerais da pesquisa, apontam-se para seus limites e para a necessidade de ampliar e aprofundar as investigações sobre os problemas de compreensão nas mais variadas situações de comunicação.

\section{A NOÇÃO DE COMPREENSÃO}

Sem pretender desenvolver uma reflexão mais profunda sobre o conceito de compreensão, em razão da extensão limitada deste trabalho, pode-se começar, dizendo que compreensão é a identificação, por parte do ouvinte, dos sentidos inerentes às escolhas do falante na formulação do texto. Kindt (2002, p. 19) resume o conceito de compreensão na seguinte fórmula: "P: $\mathrm{X} \rightarrow \mathrm{A}$ e R: A $\rightarrow \mathrm{Y}$ " e com ela sintetiza que "o produtor $\mathrm{P}$ traduz o tema/fato $\mathrm{X}$ pela formulação A e que $\mathrm{R}$ entende $\mathrm{A}$ como $\mathrm{Y}$ ”, ocorrendo, então, "em termos gerais, ainda que numa abordagem simplificada, uma compreensão desejável, quando $\mathrm{X}$ coincide com $\mathrm{Y}(\mathrm{X}=\mathrm{Y})$ ou quando $\mathrm{X}$ e $\mathrm{Y}$ sejam, em relação ao objetivo comunicacional, ao menos suficientemente idênticos $(\mathrm{X} \simeq \mathrm{Y})$ ”".

Evidentemente, não se concebem X e A como entidades autônomas. Nā verdade A (a formulação) é a própria condição de existência de X (do conteúdo), o que implica

4 "No monitoramento - de uma atividade mental permanente - confere-se o contexto, a atuação própria, mas antes de tudo a interativa, no sentido de verificar se o que está ocorrendo corresponde às expectativas ou se situa no quadro delas" (Fiehler 2002, p. 8).

5 Neste artigo não se faz distinção conceitual entre texto falado e texto conversacional e, consequientemente, também não entre expressões decorrentes dessas denominações.

${ }^{6}$ Trata-se dos inquéritos DID 121,8 e 9, transcritos da p. 21 à p.94. 
dizer que, quando, na formulação do texto, os falantes fazem escolhas, não selecionam formas para traduzir idéias ou conteúdos, mas optam por estratégias de construção de sentidos no texto, em função de seus propósitos na comunicação. E o sucesso da relação comunicativa depende diretamente da identificação e interpretação desses sentidos - da compreensão, portanto - por parte do interlocutor.

A fórmula de Kindt também não deve levar à ingênua noção de que a $\mathrm{P}$ (produtor/falante) caberia o papel atribuidor de sentidos e a R (receptor/ouvinte), o fazer interpretativo, o que conflitaria com a concepção, que aqui se preconiza, de produção interativa dos sentidos na comunicação. Na verdade, "as fases da emissão e da recepção estão em relação de determinação mútua. (...) O falante faz por antecipação certas hipóteses concernentes à interpretação e às reações eventuais do ouvinte, hipóteses que vão permanentemente influenciar as operações de codificação" (KerbratOrecchioni 1995, p. 25.). Nessa perspectiva, é característico da abordagem interacionista

que o sentido de um enunciado seja o produto de um 'trabalho colaborativo' que é construído em comum pelas diferentes partes em presença - a interação podendo então ser definida como o lugar de uma atividade coletiva de produção do sentido, atividade que implica a necessidade de negociações explícitas ou implícitas que podem chegar a bom termo ou a fracassar (é o malentendido)" (Ibid., p. 28 e 29).

$\mathrm{Na}$ linha dessas considerações decorre que a compreensão é monitorada no próprio processo de construção dos sentidos que, por sua vez, está atrelado à evolução da interação, conduzida pelos propósitos comunicacionais que a motivam. No dizer de Koch (2002, p. 17),

a compreensão deixa de ser entendida como simples "captação" de uma representação mental ou como a decodificação de mensagem resultante de uma codificação de um emissor. Ela é, isto sim, uma atividade interativa altamente complexa de produção de sentidos, que se realiza, evidentemente, com base nos elementos lingüísticos presentes na superfície textual e na sua forma de organização, mas que requer a mobilização de um vasto conjunto de saberes (enciclopédia) e a reconstrução deste no interior do evento comunicativo.

Portanto, em busca de uma comunicação bem sucedida, as atividades que os interlocutores realizam para se assegurarem a intercompreensão integram o próprio processo gerador dos sentidos.

Essas atividades podem exercer função "profilática" (Fiehler 2002, p. 9) ou terem caráter reparador. O monitoramento profilático, por meio do qual os interlocutores "tentam antecipar e evitar possíveis problemas e distúrbios de compreensão" (Ibid, p. 9), manifesta-se de duas formas: a) em atividades realizadas individualmente pelos falantes, sempre, evidentemente, em função de um interlocutor; b) em procedimentos marcados pela colaboração, quando os interlocutores, em interação explícita, asseguram-se, mutuamente, a intercompreensão. O monitoramento da compreensão tem caráter reparador, quando, um problema de compreensão surgido na evolução do texto desencadeia um trabalho interativo para sua solução. 


\section{O MONITORAMENTO PROFILÁTICO DA COMPREENSÃO}

Embora, neste trabalho, se queira dar maior atenção ao monitoramento dos problemas de compreensão, é importante que se faça uma breve análise - portanto, sem realizar um estudo exaustivo - de alguns exemplos de monitoramento profilático, seja para mostrar a relevância desse procedimento na construção do texto falado, seja para documentar a variedade de formas e de naturezas que ele pode assumir.

Observem-se, então, os seguintes segmentos de conversações:

(1) Doc. mas em geral as pessoa às vezes não consideram algumas profissões...

Inf. NÃO ah:: o que há:: é que:: é que:: normalmente sempre há um certo:: resquício assim uma::: uma certa... eu eu diria assim assim uma falta de integração um problema assim de:: ah::... como é que eu diria pra vocês... como existe discriminação racial discriminação de credo de cor existe uma certa discriminação em termos de profissão também... (Hilgert 1997, p. 59-60, linhas 360-369)

(2) Inf. [...] como o caso do Parobé por exemplo que forma aquele pessoal que tem assim profissões que ficam::

de suporte

de auxílio à profissão de nível superior (Ibid. p. 56, linhas 242-245)

(3) Inf. [...] como a nossa aqui Escola Técnica de Comércio tem formado muita gente (para lá) em nível

de Secretaria

de:: de:: pessoal de escritório... (Ibid. p. 56, linhas 234-237)

(4) Inf. [...] não só sobreviver vamos dizer assim ah:: no sentido de:: de se manter vivo mas também no sentido de trabalho esCRAvo (que se ele não trabalhasse ele era morto (Ibid. p. 59, linhas 342-345)

(5) Inf. [...] eu não definiria nenhuma profissão assim que fosse:: profiSSÃO traBAlho... que fosse pouco recomendável não não teria:: o:: nenhuma que não fosse isso em termos e:: estritos de:: de profissão de trabalho (Ibid. p. 59, linhas 354-358)

(6) Doc. Já tiveste algum problema... com o teu ap/com o aparelho de rádio assim com o aparelho em si... quando não sintonizar bem::

Inf. Não (Ibid. p. 25, linhas 131-134)

(7) Inf. olha... a Psiquiatria é uma que:: eu tenho a impressão que traz assim eh:: além de:: de uma::... de condições financeiras assim:: boas

de de de uma... realização profissional em termos econômicos há também uma realização profissional propriamente co/como médico como profissional (Ibid. p. 52, linhas 117-122)

(8) Doc. como as pessoas que nascem no dia vinte e nove de fevereiro festejam o seu aniversário?

Inf. [...] eu acho que deve festejar dia vinte e oito né? resolve o problema porque senão o caso ficaria meio gozado se o cara festejasse só de:: de:: é de dois ou dois anos $\mathrm{NÃO}$ bissexto (é) de quatro em quatro anos... (Ibid. p. 70-71, linhas 736-7443)

(9) Inf. [...] estou vendo essa Mulheres de areia porque são artistas muito bons e eles trabalham assim que parece tem então o Gianfrancesco Guarnieri 
parece um um débil mental mesmo um louco...

não é bem louco mas assim um excepcional... (Ibid. p. 34, linhas 435-440)

(10) Doc. qual o tipo mais comum de operação na garganta?

Inf. na garganta?... ah amigdaleptomia... ou seja a extirpação das amig/das amígdalas...

(Ibid. p. 90, linhas 479-482)

Em (1), revela-se o que Blanche-Benveniste (1990, p. 25-29) chama de "trabalho de denominação" na construção do texto falado. O falante, para levar a comunicação a bom termo, realiza um efetivo trabalho de busca - marcado por um contexto de tentativa e hesitação - da formulação adequada, com a qual visa a assegurar ao interlocutor a desejada compreensão do enunciado.

Em (2) e (3), o mesmo "trabalho de denominação" acontece - ainda que fora de um contexto de hesitação tão acentuado -, manifestando-se numa sucessão de termos ou expressões, os quais tendem a garantir a compreensão no conjunto da relação sinonímica ou hiperonímico-hiponímica que estabelecem entre si.

Em (4), (5) e (6), o falante elimina o risco de o interlocutor afastar-se da proposta de compreensão, por meio do uso de marcadores explícitos de definição de sentido, que, no caso, são as expressões "no sentido de", "em termos estritos", "em si".

Em (7) e (8), a compreensão é monitorada pelo recurso sucessivo à paráfrase e à correção, estratégias, aliás, com múltiplas funções na construção dos textos falados e já amplamente estudadas em falas da língua portuguesa.

Em (9) e (10) sucedem-se, respectivamente, para precisar a compreensão, uma atenuação - que assume uma função corretiva - e uma explicação de caráter definidor.

Esses exemplos de atividades monitoradoras da compreensão possuem natureza variada e, muitas vezes, não têm essa função exclusiva. São todas atividades autorealizadas pelo falante e, pelo que os dados revelam, por iniciativa dele ${ }^{7}$, com o objetivo preventivo de garantir a compreensão.

Com esse mesmo objetivo, há casos, também, em que o monitoramento da compreensão se realiza de forma interativa, quando, por exemplo, o falante, para assegurar-se de que está sendo compreendido, interpela o interlocutor a dar-lhe um feedback, conforme revelam estes segmentos:

(11) L2 - [...] é isso que eu acho eu acho que também existe um pouquinho do... do relacionamento... da pessoa... da apresentação do indivíduo dentro de determinada organização... isso você não sei se... se você prestar atenção você::... notará às vezes você possui determinadas... qualidades superiores a um competidor seu e você não é aproveitado...

L1 - ê.... são as cartas de recomendação nê? (Castilho e Preti 1987, p. 76, linhas 629-634)

(12) L1 - agora::... ((pigarreou)) inclusive falando um pouco de Medicina aí você veja como é que está a situação hoje em dia ela está:: socializada né? ... ela está:: completamente::... regularizada através de dessas interCLInicas

${ }^{7}$ É possível que alguma dessas atividades tenha sido desencadeada pelo ouvinte por meio de alguma manifestação não lingüística, própria da situação face a face em que a interação transcorreu. 


\section{L2 - exato conVÊnios (Ibid., p. 76, linhas 642-647)}

No segmento (11), L1 sinaliza, com o "sinal do ouvinte", "é”, que acompanha e compreende a fala de L2 e ainda atesta essa compreensão, resumindo a fala de seu interlocutor numa única frase: "são as cartas de recomendação". Ao terminar o turno, interpela L2 com o "sinal do falante" "né", possivelmente com o objetivo de ouvir dele uma manifestação sobre a propriedade de sua interpretação (compreensão).

No segmento (12), o monitoramento da compreensão é similar. L1, dirigindo-se a seu interlocutor com "né", manifesta-se interessado num feedback a propósito de suas considerações sobre a organização da medicina hoje em dia. Ao retrucar-lhe com "exato", L1 atesta que compreendeu a fala, ratificando-lhe esse fato por meio da palavra-síntese "convênios", por cuja prática é viabilizada a socialização da medicina.

A análise feita revela que os interlocutores, em busca de uma comunicação bem sucedida, efetivamente se empenham em garantir a intercompreensão. $\mathrm{O}$ seu fazer, nesse sentido, deixa evidente "que a compreensão aparece como algo que a qualquer momento corre risco, pode falhar, e que a comunicação por isso exige dos parceiros uma cuidadosa observação e um trabalho construtivo, a fim de chegar, na medida exigida, à compreensão" (Fiehler 2002, p.8). E sob essa ótica, o autor concebe a comunicação como "um esforço alternado imprescindível em favor de uma compreensão em constante risco" (Id., p. 8).

\section{A NOÇÃO DE PROBLEMA DE COMPREENSÃO}

Apesar de todas essas atividades destinadas a assegurar a intercompreensão dos falantes, são muito comuns os ruídos na comunicação, decorrentes de problemas de compreensão, mormente nas interações faladas. Os textos falados têm características específicas, determinadas pelas condições próprias de sua produção, particularmene pelo fato se serem produzidos em situação face a face, na qual a construção do texto coincide com o seu próprio planejamento. "Na realização da atividade comunicativa, a intenção não é anterior à formulação. A intenção é "construída" na e pela formulação, e o planejamento de uma atividade comunicativa só se completa com a construção do enunciado concluída" (Hilgert 1993, p. 107). As hesitações, desvios, interrupções, reinícios, repetições, correções e outras características do texto falado definem-no como um texto em status nascendi (Antos 1962, p. 183).

Essa natureza, aliada a uma série de outros fatores, - como a paridade ou disparidade de saber que os interlocutores dominam sobre o tema em pauta, o conhecimento que eles têm um do outro, as expectativas de um em relação ao outro, as diferenças culturais e ideológicas, a diversidade dos padrões lingüísticos em uso - põe os interlocutores, com muita freqüência, diante de problemas de compreensão.

${ }^{8}$ Marcuschi (1986, p. 61-74) considera que os "sinais do ouvinte" e os "sinais do falante" são marcadores conversacionais que, além de outras funções, são responsáveis pela orientação mútua dos interlocutores no decurso da conversação. 
O conceito de problema de compreensão pode-se definir, inicialmente, também a partir da fórmula de Kindt 2002, com base na qual se introduziu, anteriormente, a noção de compreensão. Com efeito, "ocorre um problema de compreensão em relação a A, quando P e R não conseguem fazer corresponder, na medida desejável, formulação e compreensão" (p. 19), ou seja, quando X \# Y.

$\mathrm{Na}$ linha de raciocínio desse autor, já quando entende por compreensão uma identidade ao menos suficiente entre X e Y (ver tópico 2), infere-se que a noção de problema de compreensão não se restringe à idéia da total ausência de compreensão confessa em expressões do tipo "não entendi", "não compreendi nada do que ele falou" e similares -, mas é mais ampla, abarcando a compreensão dita "parcial", "superficial", "confusa" e até mesmo os mal-entendidos, traduzidos na explicitação de hipóteses de compreensão (ver tópico 5.1) não aceitas pelo interlocutor ou de respostas equivocadas. Bazzanella e Damiano (1999, p. 832) consideram o mal-entendido como sendo uma das "fases do processo de construção de uma compreensão". Kindt (2002, p. 22), ao comentar o lado positivo de um problema de compreensão na comunicação, admite que "ele pode significar um estágio intermediário na construção da compreensão, portanto, que ele oferece, eventualmente, aos interlocutores a possibilidade de reconhecerem com quais procedimentos comunicativos se alcança a compreensão e de levá-los, na seqüência, a aplicarem esses procedimentos". Essas considerações levam a conceber o problema de compreensão como um continuum e não como o segundo pólo da relação compreensão/não-compreensão.

Assim como a compreensão resulta, implícita ou explicitamente, de um trabalho inerente ao processamento cooperativo do texto falado, também "os problemas de compreensão e os distúrbios de comunicação constituem um fenômeno interativo, pois surgem na fio conversação" (Fiehler, id., p. 8), podendo ser atribuídos ora ao falante, ora ao ouvinte, sendo, porém, sempre produtos do desdobramento conversacional.

Na opinião de Fiehler (id., p. 10), só se pode falar em problemas de compreensão quando "ambos os interlocutores têm o objetivo, o interesse e a vontade de se compreenderem e, mesmo assim, a comunicação (em determinados momentos e aspectos) não é bem sucedida". Segundo ele, quando essa disposição comum está ausente, os distúrbios de comunicação que se manifestam não podem ser enquadrados na categoria dos problemas de compreensão. Portanto, quando o ouvinte não se interessa em compreender o que o falante diz, o insucesso da comunicação entre os dois não decorre de problemas de compreensão, mas sim da falta de vontade para compreender.

Também não entram na categoria dos problemas de compreensão as ocorrências que deflagram atividades profiláticas, até porque a elas os falantes justamente recorrem para prevenir e evitar os problemas de compreensão.

Finalmente, do ponto de vista da constatação dos problemas de compreensão na construção do texto, é preciso distinguir, por um lado, os problemas constatados pelos parceiros da relação comunicativa e pelo analista (observador) do texto e, por outro, 
dos percebidos somente por este último ${ }^{9}$. Como o objetivo, aqui, é analisar e descrever o modo como os interlocutores trabalham os problemas de compreensão como instâncias metalingüísticas na construção do texto, ou seja, como eles monitoram a compreensão, quando ela constitui um problema no desdobramento comunicativo, são de interesse unicamente os problemas do primeiro grupo.

\section{O MONITORAMENTO DOS PROBLEMAS DE COMPREENSÃO}

Uma vez configurado o objeto de estudo, analisaram-se os segmentos conversacionais do corpus identificado na introdução, num total de 24 passagens, com o objetivo de classificá-las com base em características reincidentes e no grau de complexidade do monitoramento do problema de compreensão nelas focalizado. Em suma, a análise procurou estabelecer categorias de monitoramento, baseada em padrões estruturadores da sequiência monitoradora. ${ }^{10}$

\subsection{Definindo alguns termos}

Antes, porém, de apresentar essas categorias, é importante definir os principais termos que denominam os elementos que estruturam os padrões de monitoramento.

Denomina-se enunciado de referência o primeiro turno (T1) no qual, para o falante do segundo turno (T2), se situa o problema de compreensão.

$\mathrm{O}$ enunciado revelador do problema de compreensão é o turno - em geral o segundo da seqüência monitoradora - no qual se manifesta o problema de compreensão. Essa manifestação ocorre por meio de um marcador do problema ou por uma hipótese de compreensão ou por ambos.

Marcador do problema é todo elemento lingüístico cuja função explícita e específica é anunciar o problema de compreensão. Nos segmentos analisados, são marcadores do problema, por exemplo, "como estatal?" (13), " podia repetir que eu não?..." (16), "como assim" (20), "qual seria? (21)"."1

A hipótese de compreensão, embora também anuncie o problema de compreensão, tem a função mais evidente de explicitar uma possibilidade de entendimento do fato gerador do problema de compreensão. Nos segmentos analisados,

${ }^{9}$ Não raro, no desenvolvimento de uma interação, o observador (o espectador de um debate, por exemplo) constata que o ouvinte, com base no conteúdo de seu turno, não compreendeu satisfatoriamente o falante em algum aspecto de seu enunciado, e mesmo assim a interação evolui, sem que o fato seja anunciado por nenhum dos interlocutores.

${ }^{10}$ Este texto somente apresentará a análise de seqüências representativas para cada categoria.

${ }^{11} \mathrm{O}$ marcador do problema de compreensão é, em geral, uma curta expressão, mas pode ser uma pausa mais longa (17) e até ter a dimensão de um enunciado mais complexo, como se verifica no segmento (15). Ele aparece tanto como único componente de um turno, quanto associado a outros na constituição desse. À primeira vista podem se distinguir, por exemplo, marcadores específicos (os propriamente ditos) de eventuais (definidos pelo contexto). Por restrição de espaço, no entanto, não é possível desenvolver um estudo detalhado sobre os marcadores de problemas de compreensão neste artigo. É tarefa importante, porém, para um trabalho mais alentado sobre o tema da não-compreensão. 
constituem, só para exemplificar, hipóteses de compreensão as passagens: "relacionados com problema respiratório?" (18), "se ah que um:: certa situação goste de uma música?" (20), "isso referente a:: o problema dos::... dos excedentes de vestibular à:: ausência de vagas ou:: eu não entendi bem" (21). A hipótese de compreensão feita por um falante sobre o enunciado de seu interlocutor e considerada equivocada por este constitui uma das formas de mal-entendido (ver tópico 4). Nesse sentido, a primeira e a última das passagens recém transcritas são, no contexto em que se encontram, malentendidos.

Finalmente, por resposta identifica-se o enunciado que dá o monitoramento por encerrado e, conseqüentemente, o problema de compreensão como resolvido. $\mathrm{O}$ enunciado que o termo identifica não precisa necessariamente ser uma resposta a uma pergunta, embora esta seja a natureza da quase totalidade dos casos do corpus analisado.

\subsection{Apresentando as categorias}

Definidos esses termos, apresentam-se, agora, as categorias de monitoramento dos problemas de compreensão, com base nas seguintes informações: um ou mais segmentos conversacionais representativos da categoria; a análise desse ou desses segmentos; o padrão estruturador do monitoramento da categoria; e comentários.

\section{$1^{\text {a }}$. Categoria}

Constituem esta categoria as seqüências monitoradoras que já se concluem no segundo turno (T2).

(13) Doc. que você acha da televisão estatal?

Inf. como estatal? se é do Estado (tu quer dizer)?... olha eu não.. não sei se traria vantagem ou desvantagem porque até agora eu acho que não tem no Brasil né não foi adotado

Análise: (Hilgert 1997, p.37, linhas 518-522)

Doc. - pergunta

Inf. - de início não identifica o sentido do termo "estatal" (marcador de problema de compreensão), mas imediatamente lança uma hipótese de compreensão ("se é do Estado (tu quer dizer)?") e, sem esperar resposta do documentador, responde à pergunta segundo essa hipótese.

(14) Depois de ter perguntado ao informante sobre o que ele considerava ser um bom circo e obtido, como resposta, considerações sobre os personagens do circo (artistas, palhaços, animais), o documentador volta a perguntar:

Doc. e a e o de circo em si?

Inf. pra ser bom o circo? Olha... circo eu já sou diferente do cinema pra mim pode ter uma cadeira dura ruim que eu:: sei lá eu (eu estou ao menos) me sentindo bem [...]

Análise: (Ibid., p.47, linhas 861-865)

Doc - pede ao interlocutor falar agora - conforme se percebe pelo contexto - sobre o circo do ponto de vista de suas instalações. 
Inf - lança uma hipótese de compreensão ("pra ser bom o circo?") relativamente ao enfoque da pergunta do interlocutor e define sua resposta de acordo com essa hipótese, sem esperar que o documentador a confirme antes.

\section{Padrão de monitoramento da $\mathbf{1}^{\mathrm{a}}$. categoria:}

$\mathrm{T} 1$ - enunciado de referência

T2 - enunciado revelador do problema de compreensão, constituído por: (a) marcador do problema de compreensão, (b) hipótese de compreensão e (c) resposta a T1 $(=\mathrm{a}+\mathrm{b}+\mathrm{c})$ ou somente por (b) hipótese e $(c)$ resposta $(=b+c){ }^{12}$

Portanto, para a interação monitoradora do problema de compreensão se encerrar no segundo turno (T2), ele precisa necessariamente conter o elemento (c), isto é, a resposta. Mas, mesmo que T2 contenha a resposta, o monitoramento poderá evoluir, como se verá em (19), para um quarto turno.

\section{$2^{\mathrm{a}}$. Categoria}

Esta categoria se identifica no fato de $\mathrm{T} 3$ concluir o monitoramento do problema de compreensão.

(15) Inf. [...] tem aqui o:: o que o:: Astor que:: o Ástor que reformaram... que está mais ou menos depois tem aquele que reformaram também lá embaixo

Doc. por porque você acha que está mais ou menos ( ) que que você quer dizer com isso (

)

Inf. olha o ambiente dele está assim a... ah:: pô::: as cadeiras o estofa/ o estofado do chão a

Análise: pintura quer dizer [...] (Ibid., p.44, linhas 781-790)

Inf. - usa no curso de sua fala a expressão ("mais ou menos").

Doc. - não capta o sentido da expressão, no contexto em que é usada, dando a entender que deseja uma explicitação do sentido por meio de dados exemplificadores.

Inf. - dá essa explicitação.

Neste caso, T2 é exclusivamente constituído por (a).

\section{Padrão de monitoramento da $2^{\mathrm{a}}$. categoria:}

T1 - enunciado de referência.

T2 - enunciado revelador do problema de compreensão constituído pelo marcador.

$\mathrm{T} 3$ - resposta a $\mathrm{T} 1$.

T2 constitui uma intervenção no turno do interlocutor para fazer um pedido de esclarecimento ou explicitação (por meio de exemplos) sobre o sentido de um termo ou

${ }^{12}$ Daqui para frente, em favor da operacionalidade de elaboração do texto, o "marcador de problema de compreensão" e a "hipótese de compreensão" serão respectivamente denominadas de "marcador" e de "hipótese". Além disso, o marcador sempre corresponderá a (a); a hipótese, a (b); e a resposta, a (c). Essa correspondência dispensará, eventualmente, a repetição desnecessária e enfadonha de certos termos. 
expressão. Se, na seqüência do turno (T3), houver resposta satisfatória a esse pedido, encerra-se o monitoramento do problema de compreensão.

\section{$3^{\mathrm{a}}$. categoria}

A identidade dessa categoria está no fato de o terceiro turno (T3) desencadear um quarto turno (T4), que conclui a seqüência monitoradora da compreensão.

(16) Doc. quais as ligações que se pode estabelecer entre o fato de uma pessoa não ouvir e não falar?

Inf. podia repetir que eu não?...

Doc. isso aí que eu acho que não está certo... quais as ligações que se pode estabelecer entre o fato de uma pessoa... não ouvir E falar?...

Inf. quais as ligações? não ouvir e falar? ela não ouve mas fala? bom isso aí pode... tem Análise: conheço um caso aqui na Universidade [...] (Ibid., p. 87-88, linhas 403 - 411)

Doc. - pergunta.

Inf. - explicitamente declara que não compreendeu a pergunta.

Doc. - admite problemas em sua pergunta e dá-lhe, a seguir, uma formulação adequada.

Inf. - depois de pensar, repetindo para si mesmo aspectos da pergunta, finalmente responde.

T2 é constituído unicamente por (a).

São variações da estrutura de (16) os segmentos (17), (18), (19) e (20):

(17) Doc. Como você poderia identificar um rapaz que está servindo no exército e um calouro de universidade?... (longa pausa)

Doc. quanto ao cabelo...

Inf. bom o calouro de universidade.... geralmente... ou... cortam o cabelo até uma acerta

Análise: altura... [...] (Ibid., p. 79, linhas $138-143$ )

Doc. - pergunta.

---- - a longa pausa leva o documentador a inferir que o informante não compreendeu a pergunta, o que equivale a dizer que a pausa constitui um marcador de problema de compreensão.

Doc. - especifica um aspecto de sua pergunta, como recurso de retomada.

Inf. - responde, finalmente, à pergunta do documentador, encerrando a seqüência monitoradora do problema de compreensão

A variação essencial desse monitoramento em relação ao anterior está no fato de a função de $\mathrm{T} 2$ ser realizada pela pausa.

(18) Doc. e os cardíacos?... [Antes Doc. havia feito a seguinte pergunta: "quais são os problemas respiratórios mais comuns?]

Inf. relacionados com problema respiratório?

Doc. não... os cardíacos mais comuns...

Inf. problemas cardíacos? olha isso eu não:: não vou falar porque... eu não entendo... de cardiologia... nunca ouvi falar muito de problemas disso... lesões... (Ibid., p. 91, linhas $510-516)$

Análise:

Doc. - pergunta. 
Inf. - lança a hipótese de que a presente pergunta do interlocutor esteja no contexto de compreensão da pergunta anterior.

Doc. - nega essa hipótese e redefine o sentido da pergunta, reformulando-a.

Inf. - responde à pergunta reformulada.

Esse segmento se distingue dos dois anteriores por dois aspectos: T2 é constituído pela hipótese, e a retomada de T3 é antecedida pela rejeição explícita ("não") da hipótese.

(19) Doc. e:: tu achas que alguma vez o rádio assim pode:: se constituir um fator de atrito e de briga?

Inf. por causa eh um quer ouvir um programa e outro quer outro? Eu acho que sim... como a televisão também por exemplo tem uns querem ver um canal e outros querem ver outro... então sempre causa um problema hoje nós vamos ver este porque outra vez eu eu ouvi contigo o Outro programa então sempre é assim acho que rádio também a não ser que tenha dois ou três rádios na família... e aí não tem problema nenhum

Doc. é uma questão de::... de::...

Inf. como? ( ) ]

Doc. entre vizinhos por exemplo... ( )

Inf. ah de botar mais alto ou mais baixo é isso? ... ah isso também aqui em casa dá dá bastante atrito por que... gosto de ouvir mais ... gosto de ouvir o rádio um pouco alto [...] (Ibid., p. 27, linhas $188-207$ )

Análise:

Doc. - pergunta.

Inf. - lança uma hipótese de delimitação do sentido da pergunta e, sem esperar a posição do documentador, responde em sintonia com essa hipótese.

Doc. - sem negar explicitamente a resposta (como ocorrera em (18)), dá a entender, por meio da reformulação da pergunta, que ela não foi satisfatória.

Inf. - lança outra hipótese de delimitação do sentido da pergunta e, mais uma vez sem esperar a posição de Doc., responde à pergunta de acordo com a nova hipótese.

Nessa passagem, T2 é constituído pela hipótese e pela resposta a T1. O monitoramento da compreensão parece estar concluído, quando T3, numa reformulação hesitante, denuncia ser a hipótese e a resposta em T2 no mínimo insatisfatória. Esse fato desencadeia então T4, constituído por nova hipótese de compreensão e nova resposta que, finalmente, encerra o monitoramento do problema de compreensão.

Destaque-se que, além das características próprias de T2, a reformulação em T3 não vem antecedida de uma rejeição explícita a T2. A própria reformulação é o indicador de rejeição. ${ }^{13}$

(20) Doc. e tu tem assim uma estação favorita?

Inf. como assim se ah que um:: certa situação goste de uma música?

Doc. é

Inf. não não isso não tem agora TEM por exemplo no rádio quando eu escuto CERtas músicas eu me lembro de certas situações que eu passei... aí sim... isso sim mas ter assim um:: uma certa situação ouvir alguma música não (Ibid., p. 22, linhas 28 - 36)

\section{Análise:}

Doc. - pergunta.

13 Essa forma implícita de rejeição parece ser uma atitude mais branda do falante com seu interlocutor. Um estudo mais amplo precisa definir as formas de rejeição da hipótese e/ou da resposta e explicar as razões por que em certos contextos a rejeição é explícita, direta, imediata e, em outros, ela é postergada e feita com certa reserva e cuidado. 
Inf. - sinaliza, por meio de um marcador (“como assim”) que não compreendeu a pergunta , mas lança uma hipótese de compreensão.

Doc. - estranhamente aceita a hipótese, mesmo que o informante tenha, por alguma razão, identificado "situação" por "estação".

Inf. - responde em coerência com o equívoco

A variação nesse segmento se traduz no fato de T2 ser constituído por (a) e (b), e T3, por um marcador de aceitação da hipótese expressa em T2.

A análise desses cinco segmentos, considerados variações um do outro, permite agora definir o padrão de monitoramento da presente categoria.

\section{Padrão de monitoramento da $3^{\text {a }}$. categoria:}

T1 - enunciado de referência

T2 - enunciado revelador do problema de compreensão constituído só pelo marcador; só pela hipótese; pelo marcador e pela hipótese ou pela hipótese e pela resposta. ${ }^{14}$

$\mathrm{T} 3$ - retomada ${ }^{15}$ de $\mathrm{T} 1$, no todo ou em parte, por meio de reformulação.

$\mathrm{T} 4$ - resposta a $\mathrm{T} 1 / \mathrm{T} 3$.

É relevante o fato de que todas variações na $3^{\mathrm{a}}$ categoria sejam determinadas a partir de características diversas de T2. A especificidade dessa caracterização define a forma e a função correspondente de T3.

Destaque-se também que a sequiência de quatro turnos - com o anúncio do problema de compreensão em T2, isto é, imediatamente depois do turno (T1) em que foi constatado - é de longe a mais recorrente no monitoramento de problemas de compreensão, no corpus analisado. ${ }^{16}$

\section{$4^{\mathrm{a}}$. Categoria}

A necessidade de prosseguir o monitoramento, para além de quatro turnos, marca esta categoria.

(21) Doc. quais seriam as causas do problema de colocação dos formados em Escolas Superiores?...

Inf. qual seria?

Doc. os problemas as causas de problemas de colocação dos formados...

Inf. isso referente a:: o problema dos::... dos excedentes de vestibular à:: ausência de vagas ou:: eu não entendi bem

${ }^{14}$ Embora não haja nenhum registro no corpus, pode-se perfeitamente prever uma sequiência da $3^{\mathrm{a}}$. categoria, em que T2 seja constituído de $[\mathrm{a}+\mathrm{b}+\mathrm{c}]$.

${ }^{15}$ Quando o falante de T2 anuncia - por meio de um marcador ou de uma hipótese com a qual o interlocutor não concorda - que não compreendeu, no todo ou em parte, o enunciado de referência (T1), o falante de T3 (o mesmo de T1) retoma parcial ou totalmente T1. Para tanto, recorre, em geral, a repetições ou a paráfrases. Numa pesquisa mais ampla sobre o monitoramento de problemas de compreensão é fundamental um estudo detalhado das formas de retomada nesse contexto.

${ }^{16}$ Ao predomínio desse padrão também fazem referência Dascal (1999, p. 754) e Bazzanella \& Damiano (1999, p.828). 
Doc. não... (não) a colocação dos FORmados...

Inf. ah:: está o inverso qual se/ quais os problemas que surgiriam...

Doc. quais as causas ( ) do problema de não haver colocação para os formados em Escola Superior?

Inf. bom isso aí vem e/essa pergunta que vocês fazem vem eh:: em complementação à primeira observação que eu fiz... porque um dos maiores problemas que sofre o pessoal que sofre o pessoal que SAI de dentro da Universidade já formado é:: justamente é esse é problema do mercado de trabalho [...] (Ibid. p. 53-54, linhas 156177)

Análise:

Doc. - pergunta.

Inf. - manifesta que não compreendeu o sentido da pergunta no seu todo, devolvendo a pergunta com a repetição de seu segmento inicial.

Doc. - repete os dados principais da pergunta.

Inf. - apresenta uma hipótese de compreensão, mas acrescenta que ainda não compreendeu a pergunta.

Doc. - rejeita explicitamente a hipótese e retoma com ênfase um aspecto central da pergunta.

Inf. - inicia a formulação de nova hipótese de compreensão

Doc. - rejeita também essa hipótese, abortando-a bem no início de sua formulação, e repete a pergunta inicial.

Inf. - finalmente responde à pergunta, segundo a expectativa de Doc.

\section{Padrão de monitoramento da $4^{\text {a }}$. categoria:}

$\mathrm{T} 1$ - enunciado de referência.

T2 - enunciado revelador do problema de compreensão constituído por marcador.

T3 - retomada de T1 por meio de reformulação.

T4 - resposta a T1/T3 (hipótese de compreensão).

T5 - rejeita explicitamente T4, voltando a reformular T1/T3.

T6 - resposta a T1/T3/T5 (nova hipótese de compreensão).

T7 - rejeita implicitamente T6, na medida em que reformula mais uma vez T1/T3/T5.

$\mathrm{T} 8$ - resposta finalmente satisfatória a T1/T3/T5/T7.

Portanto, se T4 não responder satisfatoriamente à primeira reformulação de T1(que é T3), reformulações e respostas podem se alternar, numa seqüência mais ou menos longa, até

TN (resposta satisfatória).

\section{CONSIDERAÇÕES FINAIS}

No fechamento deste trabalho, abstraindo um pouco os traços específicos de cada categoria, cabe um olhar geral sobre elas e sobre os problemas de compreensão, além de algumas considerações sobre os limites e as perspectivas de ampliação deste estudo.

a) É preciso ter em conta que se analisaram interações com dois falantes. E cada segmento analisado se estende de um enunciado de referência (apresentando-se em quase todos os casos do corpus na forma de uma pergunta), produzido por um falante 1, até um enunciado-resposta satisfatório, produzido por um falante 2. É no intervalo desses dois enunciados que se desenvolve o monitoramento do problema de compreensão, o que implica admitir que esse monitoramento se desdobra numa sequiência mínima de dois turnos (T1 e T2). A análise mostrou que a tendência predominante é que o problema seja anunciado no segundo turno e resolvido no quarto 
turno. É esta, portanto, a dimensão mais recorrente das sequiências monitoradoras de problemas de compreensão.

b) As quatro categorias se definem, por um lado, com base na distinção de graus crescentes de complexidade das seqüências monitoradoras do problema de compreensão: a primeira se encerra em T2; a segunda, em T3; a terceira, em T4; e a quarta, em TN, já que, neste caso, é indefinido o número de turnos que podem se alternar a partir de T4. Por outro lado, cada uma das quatro categorias obtém a sua identidade das regularidades de cada padrão de monitoramento. Estas se revelam não somente na complexidade da seqüência monitoradora (número de turnos), mas, especialmente, na estruturação específica dos turnos, com destaque a T2 e T3.

c) Observe-se que as três primeiras categorias e, portanto, os padrões de monitoramento que as definem são determinados pelo segundo turno (T2). A importância deste decorre, em primeiro lugar, do fato de nele vir anunciado o problema de compreensão, seja pelo marcador, seja pela hipótese. Mas, além dessa razão, é a particularidade de sua estrutura que vai determinar a natureza do terceiro turno. Dependendo das características de T3, ele há de concluir a seqüência monitoradora ( $2^{\mathrm{a}}$. categoria) ou desencadear um quarto turno ( $3^{\mathrm{a}}$ categoria), no qual, então, a conclusão poderá ocorrer. Somente a quarta categoria não é diretamente desencadeada pelas características deT2, mas sim por T4.

d) Levando-se em conta que a peculiaridade do corpus analisado - inquéritos DID (diálogos entre informante e documentador) do Projeto NURC-RS, - é o fato de um informante entrevistar um documentador, os inquéritos se estruturam numa seqüência de perguntas e respostas. É precisamente na pergunta do documentador (T1) que o informante (T2) identifica o problema de compreensão, o qual pode surgir em diferentes níveis da construção do enunciado de referência. Bazzanella e Damiano (1999, p. 818), com base na análise de um corpus do italiano falado, propõem 5 níveis em que surgem equívocos de compreensão: o fônico, o lexical, o sintático, o semântico e o pragmático. A presente pesquisa revela - como, aliás, também a dos autores citados - que a maioria absoluta dos problemas se situa, do ponto de vista do falante de T2, no nível semântico. Com efeito, insiste este falante em solicitar, em razão do contexto, do caráter semântico vago ou da ambigüidade, que seu interlocutor delimite de forma mais precisa o sentido de palavras ou expressões por este usadas.

e) Este trabalho permitiu identificar um quadro de regularidades na estruturação dos segmentos conversacionais que monitoram problemas de compreensão, o qual dá conta dos exemplos do corpus investigado, cujas interações foram motivadas por razões específicas e vêm marcadas, por isso, por características próprias. Com certeza, esse conjunto de regularidades não explica o monitoramento dos problemas de compreensão em qualquer interação falada. Pode, no entanto, constituir um ponto de partida para analisar situações de natureza similar em diferentes tipos de interações, motivadas pelas mais variadas razões. Urge, portanto, estender a pesquisa a um leque diversificado de tipos de interações, para, com base em dados, se estabelecerem padrões gerais e particulares (específicos de determinados tipos de interação) de monitoramento de problemas de compreensão. 


\section{REFERÊNCIAS BIBLIOGRÁFICAS}

ANTOS, Gerd. (1982). Grundlagen einer Theorie des Formulierens. Tübigen, Max Niemeyer.

BAZZANELLA, Carla \& DAMIANO, Rossana. (1999). The interactional handling of misunderstanding in everyday conversations. Journal of Pragmatics 31, 817 -836.

CASTILHO, Ataliba T. de \& PRETI, Dino. (org.) (1987). A linguagem falada culta na cidade de São Paulo: diálogos entre dois informantes. São Paulo: T. A. Queiroz/ Fapesp.

DASCAL, Marcelo. (1999). Introduction: some questions about misunderstanding. Journal of Pragmatics $31,753-762$.

FIEHLER, Reinhard. (2002). Verständigungsprobleme und gestörte Kommunikation: Einführung in die Thematik. In: FIEHLER, Reinhard (org.). Verständigungsprobleme und gestörte Kommunikation. Radolfzell: Verlag für Gesprächsforschung, p. 7-15.

HILGERT, José Gaston. (1997). A linguagem falada culta na cidade de Porto Alegre: diálogos entre informante e documentador. Porto Alegre/Passo Fundo: Editora da Universidade/UPF Editora.

(1993). Procedimentos de reformulação: a paráfrase. In: PRETI, Dino (org.). Análise de textos orais. São Paulo: FFLCH/USP.

KERBRAT-ORECHIONI, Catherine. (1995). Les interactions verbales. Paris:Armand Colin, tomo I.

KINDT, Walther. (2002). Konzeptuelle Grundlagen einer Theorie der Verständigunsprobleme. In: FIEHLER, Reinhard (org.). Verständigungsprobleme und gestörte Kommunikation. Radolfzell: Verlag für Gesprächsforschung, p. 17-43.

KOCH, Ingedore. G.V. (2002). Desvendando os segredos do texto. São Paulo: Cortez.

MARCUSCHI, Luiz Antônio. (1986). Análise da conversação. São Paulo: Ática.

MOTSCH, Wolfgang \& PASCH, Renate. (1987). Illokutive Handlungen. In: MOTSCH, W. (org.) Satz, Text, sprachliche Handlung. Berlim: Akademie-Verlag, Studia Grammatica XXV, p. 11-79. 